\title{
THE
}

6-27-2016

\section{Can urban areas help sustain the preservation of open space? Evidence from statewide referenda}

\author{
Matthew Altonji \\ Corey Lang \\ University of Rhode Island, clang@uri.edu \\ Gavino Puggioni
}

Follow this and additional works at: https://digitalcommons.uri.edu/enre_facpubs

The University of Rhode Island Faculty have made this article openly available.

Please let us know how Open Access to this research benefits you.

This is a pre-publication author manuscript of the final, published article.

Terms of Use

This article is made available under the terms and conditions applicable towards Open Access Policy Articles, as set forth in our Terms of Use.

\section{Citation/Publisher Attribution}

Altonji, M., Lang, C., \& Puggioni, G. (2016). Can urban areas help sustain the preservation of open space? Evidence from statewide referenda. Ecological Economics, 130, 82-91.

Available at: http://dx.doi.org/10.1016/j.ecolecon.2016.06.026

This Article is brought to you for free and open access by the Environmental and Natural Resource Economics at DigitalCommons@URI. It has been accepted for inclusion in Environmental and Natural Resource Economics Faculty Publications by an authorized administrator of DigitalCommons@URI. For more information, please contact digitalcommons-group@uri.edu. 
Forthcoming, Ecological Economics

\title{
Can urban areas help sustain the preservation of open space? Evidence from statewide referenda
}

\author{
Matthew Altonji, Corey Lang*, and Gavino Puggioni \\ University of Rhode Island
}

June 27, 2016

\begin{abstract}
Statewide referenda for land conservation are likely to entail a disparity between people who vote on the referenda and those who live in proximity to conserved areas, which may lead to a lower probability of passage than a more local referendum. This paper examines trends in voting preferences on statewide land conservation referenda in Rhode Island using precinct-level voting data. We identify two similar referenda in 2004 and 2012 and estimate a first difference spatial regression model that seeks to understand the determinants of changes in support over time. Controlling for socioeconomic characteristics and political ideology, we find that referenda support is growing in densely populated communities relative to sparse ones, and there is a multiplicative effect of rapidly growing dense areas. This implies urban areas are becoming critical supporters for the preservation of farm, forest and open space lands, despite being nonproximate to lands at risk of development.
\end{abstract}

Keywords: land conservation; voting; referenda; spatial econometrics

\footnotetext{
* Contact author: 214 Coastal Institute, 1 Greenhouse Rd., Kingston, RI, 02881. Email: clang@uri.edu. This work was supported by the USDA National Institute of Food and Agriculture, Agricultural and Food Research Initiative Competitive Program, Agriculture Economics and Rural Communities, grant number: 2015-67024-22937.
} 


\section{Introduction}

The last century of population movement in the United States is generally characterized as first moving from rural to urban areas and then moving from urban to suburban areas - the latter generating urban sprawl. Sprawl development has serious negative economic, societal and environmental impacts, including increased congestion, pollution, and decreased access to farmland, forests and open space (Burchell et al. 2002). Society has begun to take action to combat sprawl and protect open space access through private initiatives as well as policies at all levels of government. One increasingly popular way to preserve open space is public referenda. These referenda typically raise funds through bonds or increased property taxes that can be used for acquisition of property or development rights. Nationwide, the number of referenda per year has increased from just 26 in 1988 to a peak of 215 in 2004, with over 75\% of them passing (Trust for Public Land, 2013). In fact, by 2004 more money was allocated to land conservation through referenda than federal spending (Nelson et al. 2007). ${ }^{1}$

Intuition would suggest that a likely factor in determining support for land conservation referenda is the distribution of costs of sprawl and benefits of conserved open space. Indeed, prior research has shown that proximity is a key factor. Geoghegan et al. (1997) and Irwin (2002) find that property values increase with the proportion of open space within a given radius of a property. Tyrväinen and Miettinen (2000) find that property values decrease with increasing distance from forested areas. ${ }^{2}$ For the cost of sprawl, the literature is also consistent in showing that most costs are born at the local rather than in the broader region. For example Bruekner (2000) and Deal and Schunk (2004) note that infrastructure costs appear to be born at the

\footnotetext{
${ }^{1}$ Open space conservation referenda can take on a number of forms. They vary by the type of land being conserved, ranging from farmland, forestland and wetlands to recreational spaces such as public parks and marinas. They also vary by type of legislation. Some measures are for land acquisition. Others are to continue protection of existing land, while many (including most of the measures in Rhode Island) set up funds to finance future conservation measures. The methods of finance include bonds, increased property and sales taxes, lottery funds, and royalties from resource extraction. In Rhode Island, state level referenda almost exclusively use bonds. The referenda are held at a variety of jurisdictional levels, ranging from the state level, as studied in this paper, all the way down to the municipal level. According to landvote.org, 2394 measures have been put on the ballot across the country, resulting in approved funding of over $\$ 58$ billion for land conservation since 1988. Between 1992 and 2001, the federal government spent 22.6 billion dollars on land conservation (Lerner et al. 2007) versus 21 billion dollars (Trust for Public Land 2013) from open space referenda.

${ }^{2}$ While these papers find houses capitalize open space on a local scale, it is possible or even likely that benefits extend beyond a small radius, which could provide motivation for voters not living in proximity to open space to vote in favor of a statewide referendum. However, even if benefits extend to all areas of a state, we would still expect proximate voters to benefit relatively more and thus to vote yes more often than non-proximate voters, all else equal.
} 
municipal level. These results suggest that urban communities may be less impacted by urban sprawl and less willing to support and pay for conservation.

Given the localized accrual of benefits and costs of land use change to areas on the urbanrural fringe, an open question is why are state-level referenda so popular? Why not just let communities in the urban-rural fringe hold municipal referenda and address the problem? Not only are state-level referenda common, but they typically pass, often with over $70 \%$ approval. So the question becomes can urban areas, which contain a majority of voters, help sustain nonproximate open space?

This paper examines which community characteristics lead to support of statewide conservation referenda. Our focus in this paper is Rhode Island, which despite its diminutive size is an excellent location to study. Rhode Island is the second most population dense state in the US (Wikipedia 2016) and has recently experienced tremendous land use change with 30\% of undeveloped land being developed between 1995 and 2005 (Rhode Island Statewide Planning Program 2006). In addition, Rhode Island is exceptional in its use of statewide conservation referenda - seven have been voted on since 2000, more than nearly all states.

Within this context, we are particularly interested in urban areas, which are unlikely to receive much proximate benefit from conservation, but hold a tremendous voting power and tax base that may be tapped to achieve environmental, economic and societal benefits in other communities. Figure 1 illustrates this puzzle for Rhode Island. The first map shows population density, and the second two maps show conservation spending and acres preserved for years 2000-2015 by funds raised through state level referenda. Together, the maps show an almost inverse relationship between population density and direct benefits from the conservation referenda. On one hand, the lack of conservation in urban areas makes sense given the scarcity of undeveloped land and its cost. But on the other hand, it raises the question of why urbanites would choose to vote in favor of such conservation referenda. One possible explanation is that these are the people that understand scarcity of open space and have a larger willingness to pay for conservation of the land that is left.

The purpose of this paper is to examine trends in voting preferences on statewide land conservation referenda in Rhode Island and to understand if dense and fast growing areas can help sustain open space. Because Rhode Island is so active with statewide referenda, we were able to find two referenda, 2004 and 2012, that are similar in their priority on land conservation 
and secondary funding focuses. We collected precinct-level votes and develop a methodology to match precincts to census tracts. By aggregating voting data to geographically consistent tract boundaries and focusing on two similar referenda, we effectively create a panel data set offering repeat voting observations at the tract level. We estimate a first difference specification with the change in percentage of votes in favor of the referenda as the dependent variable and the key independent variables being population density, population growth and their interaction. Our analysis also models spatial dependence with a spatial lag and spatial error and includes several socioeconomic controls.

The main findings suggest that densely populated communities have increased support for state-level referenda relative to sparsely populated communities in recent years. Further, when dense areas are growing in population, these areas are even more likely to support the measure. This indicates that state level land conservation referenda may be a valuable way to engage urban voters (and their taxes) in the process of land conservation. In addition to the main findings, our results show that areas with an increasing proportion of Democratic voters increase support of referenda. Further, we find evidence of mean reversion in voting patterns, which we interpret as evidence of voters not sorting into neighborhoods based on referenda support.

Voting has long been seen as a source of revealed preferences. Surprisingly, however, McConnell and Walls' (2005) exhaustive review of the literature on the valuation of open space included only one paragraph and one citation on voting. It has only been in recent years with increasing data availability and GIS tools that research using voting outcomes has become more prevalent. There are essentially two main strands in this literature. The first examines municipalities or counties that hold their own referenda and seeks to model support as a function of population, location and referenda characteristics (e.g., Kotchen and Powers 2006, Nelson et al. 2007, Banzhaf et al. 2010, Heintzelman et al. 2013). The second strand uses statewide referenda, partitions the state into areas with known voting outcomes, and examines which population and location characteristics drive support. The seminal work of Deacon and Shapiro (1975) examined two statewide initiatives in California, one that dealt with coastal land conservation, using voting observations at the city level. Similarly, Kline and Wichelns (1994) studied four statewide referenda in Rhode Island using town level data. Wu and Cutter (2011) advance this literature by using data with resolution at the block group level. They examine 
determinants of voting on eight separate environmentally-themed referenda in California. ${ }^{3}$ Some general results emerge from this literature. Well-educated, Democratic voters tend to favor conservation initiatives, though income has ambiguous effects. Growth in an area, be it measured by population change, new housing units or loss in undeveloped land, tends to increase support. Population density has mixed effects. Nelson et al. (2007) and Banzhaf et al. (2010) find some evidence that density has a negative effect on support. Heintzelman et al. (2013) find no effect of density. Kotchen and Powers (2006) and Wu and Cutter (2011) both find positive effects of density, and in the latter there is some evidence that the magnitude is growing over time.

Our paper contributes to this rapidly growing literature in several ways. To the best of our knowledge, this paper is the first to use panel data on land conservation referenda. As detailed above, prior studies have used cross sectional data, either from a single statewide referendum or many municipalities that have held a referendum. Using cross sectional data, there may be unobserved determinants of voting behavior, which could bias estimated coefficients. By utilizing votes in multiple time periods, our panel data approach is able to control for timeinvariant unobserved determinants of voting. Further, our panel approach enables us to examine trends in approval, and understand the determinants of changes in support, not just levels of support.

A second contribution is our development and illustration of a methodology to match precinct level voting outcomes to census tracts. When using aggregated voting data to estimate individual preferences, it is important to use as fine a scale as possible to avoid bias resulting from the ecological fallacy. Wu and Cutter (2011) and Holian and Kahn (2015) use block group level data, the finest resolution among papers in this literature. However, this data is only available for California, and other studies have relied on observations at the level of town, city or county. Our method enables researchers to use fine scale spatial units for analysis for areas outside of California.

Third, we build on two recent studies by incorporating spatial correlation into our models. Wu and Cutter (2011) and Heintzelman et al. (2013) both use spatial models and find that spatial correlation parameters are significant and their inclusion improves model fit. In our case, not only do we find improvements in model fit, but the estimated coefficients on our key

\footnotetext{
${ }^{3}$ Holian and Kahn (2015) use the same block group level voting data for California to model support for carbon mitigating policies.
} 
independent variables (density, growth and their interaction) change from statistically insignificant to significant (or vice versa) going from non-spatial to spatial. Thus, a spatial econometric modeling strategy is critical to the conclusions.

\section{Background and Data}

\subsection{Rhode Island state environmental referenda}

Rhode Island has held a remarkable 12 statewide environmental ballot initiatives since 1988, totaling over $\$ 352$ million, of which 62\% was devoted to conservation (Trust for Public Land 2013). Statewide conservation measures are not the norm in the United States; only 16 states have held one since 2000. These 16 states have held a total of 40 ballot initiatives, but Rhode Island has held 7 (or 17.5\%) of them (Trust for Public Land 2013).

In order to study how preferences may be changing in urban or growing areas, we wanted to choose a subset of the Rhode Island referenda that fit several criteria. First, we required them to be recent elections because we want to establish current trends. Second, we required the referenda to not be site specific, that is to allow funds to be spent anywhere in the state. Third, we required the referenda to be similar in language, spending amounts, and spending patterns. Fourth, the referenda needed to be held in presidential vote years, so we could control for political ideology, which is often a strong determinant of environmental preferences (Deacon and Shapiro 1975, Nelson et al. 2007, Heintzelman et al. 2013, Holian and Kahn 2015). We decided 2004 should be the furthest back in time we went to maintain the first criterion. Since 2004, three referenda were held to benefit individual sites, specifically Roger Williams Zoo in 2006, Fort Adams State Park in 2006, and Rocky Point in 2010, so these were excluded because voting patterns likely were correlated spatially with the site and thus inappropriate to compare. There were statewide referenda in years 2004, 2008 and 2012, all presidential voting years. However, 2008 requested only $\$ 2.5$ million, substantially less than 2004 and 2012, and thus we chose 2004 and 2012 as our study referenda. ${ }^{4}$ We now describe each of these referenda in detail, with information from Ballotpedia.

\footnotetext{
${ }^{4}$ In the online appendix, we estimate models with 2008 data included. Results are largely consistent, though the coefficient on the interaction between density and growth is less statistically significant than when 2008 is excluded.
} 
The short name of the 2004 referendum was "Open Space, Recreation, Bay and Watershed Protection Bonds”, which appeared on the ballot. It allowed the state to issue bonds worth no more than $\$ 70$ million, allocated in the following ways:

- \$43 million to open space, farmland preservation, and recreational development

- $\$ 19$ million to anti-pollution projects and restoration activities benefiting Narragansett

Bay and state watersheds

- $\$ 8$ million to acquisition of land for groundwater protection and supply

The 2004 referendum passed with $70.8 \%$ approval.

The short name of the 2012 referendum was "Issue general obligation bonds (up to $\$ 20,000,000$ ) for environmental and recreational purposes”, which appeared on the ballot. As made clear in the title, it allowed the state to issue bonds worth no more than \$20 million, allocated in the following ways:

- \$2.5 million to State Land Acquisition - Open Space

- $\$ 4.5$ million to Farmland Development Rights

- \$2.5 million to Local Land Acquisition Grants

- \$4 million to Narragansett Bay and Watershed Restoration

- \$5.5 million to Local Recreation Grants

- $\$ 1$ million to Historic/Passive Parks

The 2012 referendum passed with 69.8\% approval.

From the descriptions, it is evident that these two referenda are in large part quite similar. Further, based on conversations with land trust officials, our impression is that voters viewed these two referenda as very similar. Both referenda devote the largest share of funds towards land conservation. Additional priorities in both years are recreation and water, specifically Narragansett Bay, watersheds and groundwater. However, each of these additional priorities could yield action anywhere in the state, as the Narragansett Bay watershed includes most of the state and recreation can happen anywhere. ${ }^{5}$ Groundwater protection is actually more likely to impact rural areas because Providence and surrounding urban areas rely on surface water (the

\footnotetext{
${ }^{5}$ In the introduction, we hypothesize that open space conservation could benefit voters not living in proximity to the open space. We see that this is also true for the secondary proposed actions of the referenda. This is particularly true for recreation spending, for which people may travel from many parts of the state to visit. However, our logic for open space benefits applies here too - while recreation areas/programs may provide benefits for everyone in the state, those living in proximity will benefit more. Tapsuwan et al. (2012) offer empirical support of localized benefits of recreation.
} 
Scituate Reservoir). The only true priority difference between the referenda is the addition of historic/passive parks in 2012, which are more likely to occur in rural areas. Thus, based on the described funding priorities, most action resulting from passage is far more likely to impact rural areas, and based on changes in funding priorities across years, we see no reason why support would increase in urban areas.

Having settled on 2004 and 2012, we gathered precinct level voting data for these referenda from the Rhode Island Board of Elections. Voting outcomes for these referenda form the dependent variable in our analysis. This research seeks to explain changes in voting outcomes across these years, so we need to be able to match the precinct voting data with population and socioeconomic variables. While it may be ideal for the unit of analysis to the precinct, the Rhode Island Board of Elections was unable to provide an outline of the precinct boundaries. However, they were able to provide the address of the polling location for each precinct. Thus, we developed a method to match polling locations with census tracts. Using GIS, we first geocoded the polling address in order to obtain spatial coordinates of each location. Second, we created Theissen polygons around each precinct address, essentially creating artificial boundaries that were halfway between each precinct point. Third, the newly created precinct Theissen polygons were clipped such that they never cross municipal boundaries. Fourth, we calculated the area of overlap between 2000 census tract boundaries and the approximated precinct boundaries. Fifth, for each tract, we calculated the proportion of area comprised of each precinct. Finally, we use the area proportions as weights and take a weighted average of precinct voting outcomes to arrive at an estimated voting outcome for each tract, which is our unit of analysis. ${ }^{6}$ Figure 2 illustrates this process with fictitious tracts and precincts.

\subsection{Density, growth and socioeconomic data}

The key independent variables for our analysis are population density and population growth. Using Geolytics Neighborhood Change Database, we obtained population counts for years 1990 and 2000 for Census 2000 tract boundaries. For population data in 2010, we downloaded data from the 2010 Decennial Census. Tract boundaries changed between 2000 and

\footnotetext{
${ }^{6}$ A key factor to consider is the size of the study area, particularly when using the "median voter framework". In the absence of knowledge about the socio-economic characteristics of all voters, the median voter framework implicitly assumes that the voters within a given geographic entity have uniform characteristics (Balsdon 2012). Not surprisingly this assumption generally worsens with larger geographic areas (Wu and Cutter 2011). For this reason the current research seeks to assess voting patterns at as fine a level as possible, and we follow in this vein.
} 
2010, so we downloaded this data at the block group level and used GIS to estimate 2010 population for 2000 boundaries. ${ }^{7}$ Using 2000 and 2010 data, we use linear interpolation to estimate tract population in years 2004 and 2012. We then divide these by tract area to get density. To estimate growth for each tract and each referendum year, we estimate the change in population over the prior 10 year period. For referendum year 2004, for example, we linearly interpolate population to 1994 and 2004 and difference those.

In order to control for other possible determinants to voting behavior, we also gather socioeconomic data from the 2000 Decennial Census (Geolytics) and the 2008-2012 American Community Survey. ${ }^{8}$ These include the percentage of high school and college graduates, median household income, unemployment rate, percentage of the population under 18, percentage of the population over 65 and percentage of the population that is black or Hispanic. We treat the ACS data as being from the year 2010, and linearly interpolate these variables to years 2004 and 2012.

There were many differences between the elections in 2004 and 2012: presidential candidates (most notably the addition of Barack Obama), local races, and non-environmental referenda. All of these factors could cause changes to who decides to vote, which in turn could bias our findings. In order to mitigate this possibility, we control for the proportion of votes going to the Democrat presidential candidate, voter turnout and the proportion of the tract that is black or Hispanic. The last variable comes from the Census data explained above. We additionally gathered voting outcomes in presidential races and total votes cast at the precinct level to create important control variables. We use votes cast for the two major political parties in the presidential election to form a variable percent Democrat. We divide the total votes cast by total population to get a measure of percent turnout. ${ }^{9}$

\footnotetext{
${ }^{7}$ This process is similar to that used to match precincts to tracts. In GIS, we overlaid census tract 2000 boundaries and Census block 2010 boundaries as shapefiles. Then we used the Tabulate Intersection tool to calculate the area of overlap between boundaries. Then we estimated the population of each tract based on the area weighted average population of the full and partial blocks within it. This estimation strategy assumes homogenous spatial distribution of population within blocks, which is fairly benign given the small scale of blocks.

${ }^{8}$ The American Community Survey was downloaded at 2010 Census Block resolution. Similar to the process described for population data, we matched these blocks to Census tract 2000 boundaries to estimate socioeconomic characteristics of each tract in Rhode Island.

${ }^{9}$ This will necessarily be an underestimate of voter turnout, as the total population is greater than total eligible voters, but we do not have that data by precinct. We additionally estimated models using voter turnout as the dependent variable to test if selection across elections was an issue. The results suggest that none of the key coefficients (density, growth and their interaction) were significant predictors of turnout, suggesting any selection present in those two elections is not driven by those variables. These results are available by request.
} 
Table 1 presents summary statistics for all of the variables used in the analysis. Values are given for the year 2004 unless otherwise noted. Average support for conservation referenda is high at $71.5 \%$ in 2004, and on average barely changes in 2012. The average tract in our sample has a density of 5200 people/square mile (Rhode Island is the second most dense state behind New Jersey), but very little growth on average. Rhode Island tends to be a Democratic stronghold and in 2004 nearly 62\% of the vote went to John Kerry. About 9\% of the population is black or Hispanic, about $80 \%$ have at least a high school degree and $20 \%$ have at least a college degree. Median household income is about \$50,000 and the unemployment rate is 6.2\%. $21 \%$ of the population is under age 18 and $14 \%$ is over 65.

While Table 1 indicates that average support for conservation referenda is high and there is little change in aggregate support between 2004 and 2012, Figure 3 reveals substantial heterogeneity in both aspects. The left panel shows that average approval ranged from $59.4 \%$ to 89.3\%. Support tended to be highest near Providence and in the areas near Narragansett Bay. In terms of changes in support, some tracts reduced support by as much as $11.4 \%$ and some increased support by as much as $15.3 \%$. The areas that increased support the most are almost all in or around Providence.

While these figures suggest that urban areas tend to have high and growing support for open space measures, a thorough multivariate analysis is needed to test whether it is the urbanness that drives that support or other factors such as Democratic vote share, which is also highest in urban areas. Section 3 details our multivariate analysis that seeks to disentangle these factors.

\section{Methodology}

We use a first difference approach to examine voting trends in Rhode Island state level open space referenda. The dependent variable is the change in percent yes votes on the referenda $\left(\Delta \%\right.$ approve $_{i}$ ). Our basic model seeks to understand whether the density or recent population growth of areas are predictors of changes in preferences for open space referenda. One hypothesis is that people in dense areas do not have the same access to open space amenities and thus may value them more. In a similar logic, people living in rapidly growing areas may value open space lands because they are seeing undeveloped land disappearing. However, the logic of preference based sorting may suggest that urbanites care less about open space amenities because 
they chose to locate in the city, so it is a priori ambiguous how these variables will impact voting. Our base model is as follows:

$$
\begin{gathered}
\Delta \text { \%approve }_{i}=\beta_{0}+\beta_{1} \text { density }_{i}+\beta_{2} \text { growth }_{i}+\beta_{3} \text { density }_{i} * \text { growth }_{i} \\
+\Delta \mathbf{X}_{i} \boldsymbol{\delta}+\varepsilon_{i}
\end{gathered}
$$

where density $_{i}$ is population density of tract $i$, growth $_{i}$ is population growth, and $\mathbf{X}_{\boldsymbol{i}}$ is a vector of socioeconomic and voting controls. We not only include growth and population as explanatory variables, but also their interaction because there could be a multiplicative effect (and not just additive) of density and growth. We transform density dend $_{i}$ growth $_{i}$ into deviation from mean form such that $\beta_{1}$ through $\beta_{3}$ are interpreted as marginal effects at the mean.

The first difference approach is important because not only does it model trends over time, but it controls for unobservable, time-invariant factors at the tract level. If there are determinants of voting that are unobservable to the researcher and correlated with independent variables, then the resulting coefficients will be biased. However, our model should greatly reduce, if not eliminate, that bias.

While Equation (1) presents the motivation for our analysis, it is just an intermediate step towards our spatial model. It is likely important to control for spatial autocorrelation between the dependent variable (spatial lag) and allow for correlation between the error terms (spatial error). Spatial dependence will occur if the voting trends of tracts are influenced by the trends in nearby tracts, perhaps due to shared benefits from conservation or campaign efforts by various environmental interest groups. Spatial dependence is accounted for by introducing a spatially lagged dependent variable.

Incorporating spatial error is necessary when error terms of nearby geographic areas are correlated due to unobserved, spatially referenced variables. This correlation violates the assumption of independent error terms necessary for OLS. Spatial error dependence could occur if there are unobserved and correlated attributes of neighboring communities that would lead to an increase or decrease in approval rates for land conservation. It could also occur if the data generating process does not match up with the geographic boundaries used (Bivand et al. 2013). This could be the case here because in many cases votes at the precinct level are divided between adjacent census tracts. 
Both a spatial lag and spatial error term are incorporated using a mixed regressive spatial autoregressive model with a spatial autoregressive disturbance (SAC or SARAR). The spatial version of our first difference model is as follows:

$$
\begin{gathered}
\Delta \% \text { approve }_{i}=\rho \boldsymbol{W}_{\mathbf{1 i}} \boldsymbol{\Delta} \% \text { approve }+\beta_{0}+\beta_{1} \text { density }_{i}+\beta_{2} \text { growth }_{i} \\
+\beta_{3} \text { density }_{i} * \text { growth }_{i}+\boldsymbol{\Delta} \mathbf{X}_{\boldsymbol{i}} \boldsymbol{\delta}+\lambda \boldsymbol{W}_{2 i} \boldsymbol{\varepsilon}+\varepsilon_{i}
\end{gathered}
$$

where $\boldsymbol{W}_{1 i}$ and $\boldsymbol{W}_{\mathbf{2}}$ is the $i^{\text {th }}$ row of the spatial weight matrices for the spatial lag and spatial error terms, respectively. A positive value of $\rho$ indicates that the percent approval in tract $i$ is positively influenced by the percent approval in neighboring tracts. A positive value of $\lambda$ indicates that errors in nearby tracts are positively correlated, likely resulting from unobserved variables that are correlated across space.

This model requires two separate spatial weights matrices, $\boldsymbol{W}_{\mathbf{1}}$ and $\boldsymbol{W}_{\mathbf{2}}$, which assume the degree of relationship between different geographic entities (in this case, tracts). The first step is to create a neighbor object declaring which areas will be considered neighbors with each other. For our primary specification, we follow Wu and Cutter (2011) and select the ten nearest tracts as neighbors for the spatially lagged dependent variable and select all tracts as neighbors for the spatial error. Then, weights between neighbors are set using the inverse distance. The weight placed on tract $i$ located a distance $d$ from tract $j$ will be $\mathrm{w}_{\mathrm{ij}}=\mathrm{d}_{\mathrm{ij}}{ }^{-\mathrm{p}}$, where $\mathrm{p}$ is the inverse distance weighting power. $\mathrm{p}>0$ ensures that nearby areas are given more weight than those further away. Our main specification uses $\mathrm{p}=1$, similar to Wu and Cutter (2011) and Heintzelman et al. (2013). Admittedly, the selection of neighbors and the inverse weighting power is somewhat arbitrary. Thus, in the results section, we test the impact of using different spatial weight formulations for both the spatial error and spatial lagged dependent variable, and find that results are nearly identical.

In addition, we estimate a cross sectional regression with the same independent variables as our first difference models. This model serves two purposes, both related to comparisons. First, all existing literature has examined voter preferences using a cross sectional approach, and thus we can use these results obtained using state level referenda in Rhode Island to those obtained from other states or national level data sets of municipal referenda. Second, we can compare the cross sectional and first difference results to ascertain what additional insights are gleaned by using the first difference model. Our cross sectional model is: 


$$
\begin{gathered}
\text { \%approve }_{i}=\rho \boldsymbol{W}_{\mathbf{1 i}} \% \text { approve }+\beta_{0}+\beta_{1} \text { density }_{i}+\beta_{2} \text { growt }_{i} \\
+\beta_{3} \text { density }_{i} * \text { growth }_{i}+\mathbf{X}_{\boldsymbol{i}} \boldsymbol{\delta}+\lambda \boldsymbol{W}_{\mathbf{2 i}} \boldsymbol{\varepsilon}+\varepsilon_{i}
\end{gathered}
$$

We estimate this equation separately for the 2004 and 2012 election, using density, presidential voting, turnout and socioeconomic data from the respective year as controls.

\section{Results}

\subsection{Spatial first difference model}

Table 2 presents results from estimating Equation (2), our spatial first difference model. ${ }^{10}$ The first three columns present three different specifications that differ in the covariates included. Column 1 includes only our key independent variables of density, growth, and their interaction; Column 2 adds all voting and socioeconomic controls except \%approve 2004; and Column 3 finally adds \%approve 2004. Each specification additionally includes spatial lag and spatial error terms. The coefficients shown in the first three columns are the direct effects of a given variable on change in \% approve. Through the spatial lag term, a direct effect sets in motion indirect effects when the direct effect spills over into neighboring areas (LeSage and Pace 2009). Column 4 shows total effects, the sum of direct and indirect effects, for the specification in Column 3. More details on this calculation are given below.

The coefficient on density is positive and statistically significant in all specifications. The results of Column 3 suggest that a 1000 person/sq. mi. increase in population density is associated with a 0.339 percentage point increase in approval. In contrast, the coefficient on growth is never statistically significant and changes signs across specifications, suggesting growth has no effect by itself. However, the coefficient on the density-growth interaction is positive and statistically significant across all specifications. This variable is more difficult to interpret. The coefficient of 0.012 in Column 3 suggests that for tracts with a $1 \%$ above average growth rate, the effect of an additional 1000 people/sq. mi. above the mean density increases \% approve 0.012 percentage points, which added to the level effect of density yields a total increase of 0.351 percentage points. In general, the positive sign across the columns indicates that the effect of density on voter approval is larger in areas with high population growth. ${ }^{11}$

\footnotetext{
${ }^{10}$ The Langrage multiplier LM and Global Moran's I tests for spatial autocorrelation indicates that both spatial errors and spatially lagged dependent variables should be accounted for in the first difference model.

${ }^{11}$ While we use \%approve as our dependent variable, other papers in this literature have used the log odds ratio, which equals $\log$ (\%approve/(1-\%approve)) and is theoretically grounded in the binary choice of individual voters.
} 
Turning to the other covariates, only a few show a statistically significant impact on changes in conservation approval. The coefficients on $\Delta \%$ Democratic Vote are predictably positive and suggest that a 1 percentage point increase in Democratic presidential votes from 2004-2012 is associated with a 0.382 to 0.407 percentage point increase in land conservation approving votes over the same time period. The other two variables that yield consistently significant coefficients are \% high school graduate (positive) and \% under 18 (negative). The \% under 18 result is surprising, but perhaps families with children are also more financially constrained than those without or families are more supportive of further development. In general, very few socioeconomic characteristics have a statistical effect on changes in voting patterns. This finding stands in contrast to much of the prior literature on the determinants of environmental voting (e.g., Kotchen and Powers 2006, Nelson et al. 2007), and it is likely due to our method and data. While there is substantial cross sectional variation in socioeconomic characteristics, which is the variation used in prior work, there is unlikely to be as much time variation, which is the variation we use to identify coefficients. Importantly, the insignificant coefficients do not imply that socioeconomic variables are not determinants of environmental voting patterns. Regardless, the focus of our study is on density and growth, and the socioeconomic variables serve as controls so we can better isolate the impact of the key variables.

In Column 3, we additionally include \% approve 2004 as a covariate. This variable tests whether areas of high support in 2004 became more supportive, less supportive or stayed the same. If high support areas became more supportive, this could be evidence of preference based sorting and an electorate that is polarizing. Lang and Pearson-Merkowitz (2015) examine presidential voting at the county level for the whole United States using a similar specification of first difference with initial year voting as a key independent variable. They find that in the 1970s and 1980s, counties tended to revert to the mean, but in the last two decades counties have become more polarized. Thus, we include \% approve 2004 to test whether a similar phenomenon is occurring with environmental voting. The estimated coefficient in Column 3 indicates that a $1 \%$ increase in the 2004 votes is tied to a 0.271 percentage point decrease in \% approve. This suggests that there is no sorting occurring based on preferences for land conservation. In fact, \%

We favor using \%approve for ease of interpretation, but for sake of comparison, we present analogous results in the online appendix using log odds as the dependent variable. Results are consistent with Table 2. 
approve is mean reverting between 2004 and 2012, suggesting a random component to voting outcomes.

The spatial lag and error coefficients, shown at the bottom of the table, are significant in all columns and highly significant in most cases. The magnitude of the spatial lag is fairly consistent across columns, but as more covariates are added it declines to 0.479 in Column 3 . On the other hand, the spatial error term grows substantially as covariates are added and equals 0.908 in Column 3. This pattern may indicate that controlling for more variation in changes in \% approve with covariates actually allows the spatial structure to take shape.

We turn now to discussing total marginal effects. The total effect of an explanatory variable on the dependent variable can be divided into a direct effect, in which a change in the variable directly impacts the explanatory variable, and an indirect effect, in which it affects the explanatory variable indirectly by first affecting outcomes in nearby communities. Columns 1-3 of Table 2 are direct effects, which are generated through standard spatial regression techniques. In Column 4, we report the total effect from the Column 3 specification. ${ }^{12}$

Examining the results we see that the sign and significance of the total effects are the same as in Column 3, but the magnitude is larger for all coefficients. This makes sense because the spatial lag is positive, so indirect spillovers will have an additive effect. The results suggest that indirect effects are substantial, often being of similar magnitude as the direct effect, which makes the total effect almost double what is in Column 3. Thus, density and its interaction with growth are even larger determinants of changes in \% approval when considering spillovers.

\subsection{Robustness of spatial assumptions}

As stated in Section 3, our choice of spatial weights matrices is somewhat arbitrary, and thus it is important to explore different spatial formulations to make sure that results are not significantly altered by the choice of spatial formulation. Table 3 presents results for four alternative sets of assumptions about the structure of the spatial lag and spatial error matrix. Column 1 replicates the main results shown in Table 2 Column 3 for ease of comparison. Column 2 is similar to Column 1 but defines the nearest 20 tracts as neighbors for the spatial lag, as opposed to just the nearest 10 as in Column 1. Column 3 defines the nearest 20 tracts as

\footnotetext{
${ }^{12}$ The effects are generated through the impacts function of the SPDEP package in R. (For more information, see Bivand and Piras 2015, Elhorst 2012, and Piras 2014).
} 
neighbors for both the spatial lag and spatial error. Column 4 returns to the Column 1 definition of neighbors (10 nearest for spatial lag and all tracts for spatial error), but uses and an inverse distance weighting power of two, meaning that the modeled correlation of neighbors decays much quicker with distance. Column 5 uses identical weights matrices for the spatial lag and spatial error, which are constructed as follows: for all tracts find the minimum distance between that tract and a neighbor, then take the maximum of those minimums, then categorize tracts as neighbors if they are within that distance.

The coefficients on density, growth and their interaction are remarkably consistent across columns in terms of magnitude and statistical significance. While the alternative spatial approaches are far from exhaustive, these results suggest that the choice of spatial weights object is not important for our conclusions. One interesting difference between models is that the coefficient on the spatial lag is insignificant for Columns 4 and 5, which indicates that the choice of weights and neighbor objects does have an effect on the estimated degree and type of spatial correlation.

\subsection{Non-spatial first difference model}

Table 4 presents results from estimating Equation (1), the non-spatial version of the first difference model. Three columns are presented that are analogous to Columns 1-3 of Table 2. Similar to Table 2, density has a consistently positive and significant effect on the change in \%approve. In contrast, however, the interaction between density and growth loses statistical significance as more covariates are added. The coefficient on growth by itself gains statistical significance in the final column.

In sum, comparing Table 4 with Table 2, we clearly see that spatial modeling is important in this context. Moving from a non-spatial to spatial specification, growth loses significance but the density-growth interaction gains significance. Further, the magnitude of effects grows substantially comparing non-spatial coefficients to the total marginal effects of Table 2. Thus, some of the findings are different once spatial dependence is accounted for.

\subsection{Spatial cross sectional model}

We additionally estimate cross sectional models for 2004 and 2012, separately, with \% approve as the dependent variable in both cases. We do this for two reasons. First, these models 
are more directly comparable to prior literature. Second, we can compare our cross sectional and first difference results to see what additional information is gleaned from the panel data approach.

Table 5 presents results from estimating Equation (3); the same spatial weights matrices are used here as in Table 2. Column 1 presents estimates of the direct effects for the 2004 referendum, and Column 3 does the same for the 2012 referendum. Columns 2 and 4 give total effects after accounting for the multiplier effect of spatial spillovers. ${ }^{13}$

The 2004 results indicate that recent population growth is associated with increases in \% approve. In both years, density and the interaction of density and growth are insignificant. Consistent with the growth findings, Nelson et al. (2007) find that recent housing growth is correlated with higher approval of municipal referenda. Nelson et al. (2007) and Kotchen and Powers (2006) also find that density has no effect on voting, though Kotchen and Powers find density actually has a negative effect when just examining Massachusetts and New Jersey towns.

Educational attainment is positively correlated with \% approval in both years, which is similar to results found in Nelson et al. (2007). In 2012, approval is increasing in income; Kotchen and Powers find similar evidence. Democrat vote is again positively correlated with approval in both years, though substantially more so in 2012. This could be due to differences in candidates or many other differences between these elections. Lastly, the results suggest that larger proportions of the young and old lead to lower approval.

While the results of Table 5 tend to support prior cross sectional findings in the literature, there are considerable differences in the conclusions that can be drawn with these models versus the first difference models of Table 2. First and foremost, the results are basically inverted for our variables of interest (density, growth and their interaction). In the cross sectional model, growth is the only significant determinant of conservation support, and in the first difference model density and density*growth are both significant. Given these differences in results, it is likely that the cross sectional models would not predict the increase in support in dense areas. Further, in the cross sectional models, several socioeconomic characteristics (e.g., education, income) are statistically significant, but are insignificant in the first difference model. As discussed in Section 4.1, this could imply that these socioeconomic characteristics are not

\footnotetext{
${ }^{13}$ Table A4 in the online appendix presents pooled cross sectional models. The results are qualitatively the same, but coefficients tend to be more statistically significant, likely due to the larger sample size and consistency of determinants across years.
} 
actually strong drivers of support, but instead are correlated with unobservable determinants of support. However, another interpretation is that there is insufficient within-tract, temporal variation to identify the true impact of these variables.

\section{Conclusion}

Measuring preferences for open space is important in order to correct market failures and conserve a socially optimal quantity of open space. One source of revealed preferences is voting outcomes on conservation referenda. This paper builds on prior work and suggests an added dimension to the existing literature by looking at trends in referenda approval over time through a first difference specification. Using this new framework, several key findings emerge. Population density is consistently tied to increasing levels of support over time, particularly in densely populated communities that are also experiencing growth. In our spatial model, we find statistically significant spatial error and lag coefficients, which indicate that both observed and unobserved spillover effects are occurring between nearby neighborhoods. This could suggest voters forming preferences based on nearby communities' density, growth or open space preservation or exposure to campaign efforts pulling these communities together.

Our findings offer potential policy lessons. The first is to answer the question posed in the title of this paper: yes, urban areas can help sustain open space lands. Despite non-proximity to already conserved and possible conservation sites, support for conservation is growing in urban areas relative to rural areas. It may be that urban residents place a higher value on open space due to their experience with scarcity of undeveloped land. In this light, statewide referenda are an excellent means to harness urban voters' support and tax dollars. On the flip side, our results show that rural areas and especially rural areas not experiencing growth have declining support for conservation referenda relative to other areas.

It is important to qualify our results with two caveats. First, we cannot claim that our results are causal. Despite our panel approach that captures omitted variable bias from timeinvariant factors, there may still be unobserved determinants of voting that are correlated with our explanatory variables. That being said, we have complete confidence in our models providing a descriptive function to explain what has happened. Second, our results may not generalize to other states. Rhode Island is a small state with only one real city, Providence. Thus, all of our high density areas are drawn from in and around Providence. If there is something 
unique about Providence in relation to other cities, then it may not be the case that conservation preferences are growing in other urban areas. However, while Providence is just one city, our data comprises unique observations for many dozens of different neighborhoods within that urban area with widely varying socioeconomic characteristics, so this may help generalizability. Further, based purely on anecdotal evidence, many urban areas around the US are becoming more environmentally friendly (e.g., bike lanes, community gardens), so it is entirely plausible that the trend we observe in Rhode Island is happening elsewhere.

While this paper makes several contributions to the literature, the findings also raise additional questions for future research in land conservation voting. Specifically, an improved assessment of voter rationale is needed. Future studies could use survey methods to examine the degree to which and the reasons why people in different community types value open space. Do they actively visit preserved land outside of their municipalities, or do they simply derive nonuse value from the existence of open space? What are voters' expectations about the location of referendum-approved spending and its impact (such as house price appreciation, local food or environmental quality)? Studies could also look for signs of referenda voting becoming more partisan by seeing how support among Democratic and Republican voters is changing over time. 


\section{References}

Balsdon, E. M. (2012). "Property Value Capitalization and Municipal Open Space Referenda.” Land Economics, 88(2), 201-232.

Banzhaf, H. Spencer, Wallace E. Oates, and James N. Sanchirico. "Success and design of local referenda for land conservation." Journal of Policy Analysis and Management 29, no. 4 (2010): 769-798.

Bivand, R. S., Pebesma, E. J., Gómez-Rubio, V., \& Pebesma, E. J. (2013). Applied spatial data analysis with $R$ Second Edition (Vol. 747248717). New York: Springer.

Bivand, Roger, and Gianfranco Piras. "Comparing implementations of estimation methods for spatial econometrics." Journal of Statistical Software, 2015, 63(18).

Bruekner, J “Urban Sprawl: Diagnosis and Remedies,” International Regional Science Review. 2000. 23. 160- 171.

Burchell, Robert W., George Lowenstein, William R. Dolphin, Catherine C. Galley, Anthony Downs, Samuel Seskin, Katherine Gray Still, and Terry Moore. "Costs of sprawl--2000." (2002).

Deacon, Robert and Perry Shapiro. "Private Preference for Collective Goods Revealed Through Voting on Referenda.” American Economic Review, 65(5), 1975, pp. 943-955.

Deal, Brian, and Daniel Schunk. "Spatial dynamic modeling and urban land use transformation: a simulation approach to assessing the costs of urban sprawl." Ecological Economics 51, no. 1 (2004): 79-95.

Elhorst, J. Paul. "Matlab software for spatial panels." International Regional Science Review (2012): 1-17.

Geoghegan, J., L. A. Wainger, and N. E. Bockstael. 1997. “'Spatial Landscape Indices in a Hedonic Framework: An Ecological Economics Analysis Using GIS.’ Ecological Economics 23 (3): 251-64.

Heintzelman, Martin D., Patrick J. Walsh, and Dustin J. Grzeskowiak. "Explaining the appearance and success of open space referenda." Ecological Economics 95 (2013): 108-117.

Holian, Matthew J., and Matthew E. Kahn. "Household Demand for Low Carbon Policies: Evidence from California.” Journal of the Association of Environmental and Resource Economists 2, no. 2 (June 2015): 205-34.

Irwin, Elena G. "The effects of open space on residential property values." Land economics 78, no. 4 (2002): 465-480.

Kline, J., \& Wichelns, D. (1994). Using referendum data to characterize public support for purchasing development rights to farmland. Land Economics, 223-233.

Kotchen, Matthew J., and Shawn M. Powers. "Explaining the appearance and success of voter referenda for open-space conservation." Journal of Environmental Economics and Management 52, no. 1 (2006): 373-390

Lang, C., \& Pearson-Merkowitz, S. (2015). "Partisan sorting in the United States, 1972-2012: New evidence from a dynamic analysis.” Political Geography, 48: 119-129. 
Lerner, Jeff, Janet Mackey, and Frank Casey. "What's in Noah's wallet? Land conservation spending in the United States." BioScience 57, no. 5 (2007): 419-423. Page 420

LeSage, J. P., and R.K. Pace. (2009). Introduction to spatial econometrics. Boca Raton, FL: Chapman \&Hall/CRC.

McConnell, Virginia, and Margaret A. Walls. The value of open space: Evidence from studies of nonmarket benefits. Washington, DC: Resources for the Future, 2005.

Nelson, Erik, Michinori Uwasu, and Stephen Polasky. "Voting on open space: What explains the appearance and support of municipal-level open space conservation referenda in the United States?" Ecological Economics 62, no. 3 (2007): 580-593

Piras, Gianfranco. "Impact estimates for static spatial panel data models in R." Letters in Spatial and Resource Sciences, 7.3 (2014): 213-22

Rhode Island Statewide Planning Program. "Land Use 2025: Rhode Island State Land Use Policies and Plan” Report Number 109; State Guide Plan Element 121. April 13, 2006.

Tapsuwan, S., MacDonald, D. H., King, D., \& Poudyal, N. (2012). A combined site proximity and recreation index approach to value natural amenities: An example from a natural resource management region of Murray-Darling Basin. Journal of environmental management, 94(1), 69-77.

Trust for Public Land. LandVote Database, accessed December 1, 2013.

Tyrväinen, Liisa, and Antti Miettinen. "Property prices and urban forest amenities." Journal of Environmental Economics and Management, 39, no. 2 (2000): 205-223.

Wikipedia contributors, "List of U.S. states by population density," Wikipedia, The Free Encyclopedia, https://en.wikipedia.org/w/index.php?title=List_of_U.S._states_by_population_density\&oldi $\mathrm{d}=708529464$ (accessed March 12, 2016).

Wu, X., \& Cutter, B. (2011). Who votes for public environmental goods in California? Evidence from a spatial analysis of voting for environmental ballot measures. Ecological Economics, 70(3), 554-563. 


\section{Figures and Tables}

Figure 1: Spatial distribution of population and conservation effort

\section{Population density}

People per sq. mile

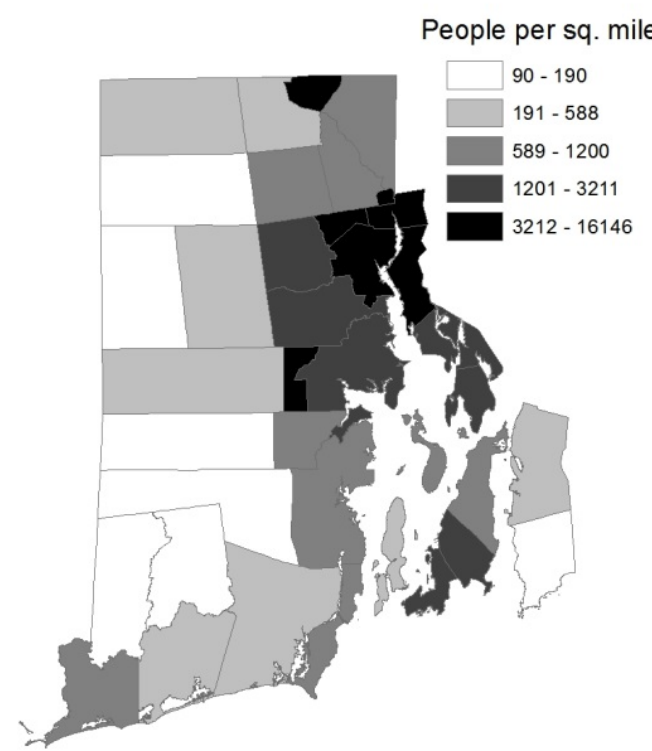

Land conservation

Acres per capita

$\square .000-0.001$

$0.002-0.009$

$0.010-0.025$

$0.026-0.116$

$0.117-0.373$

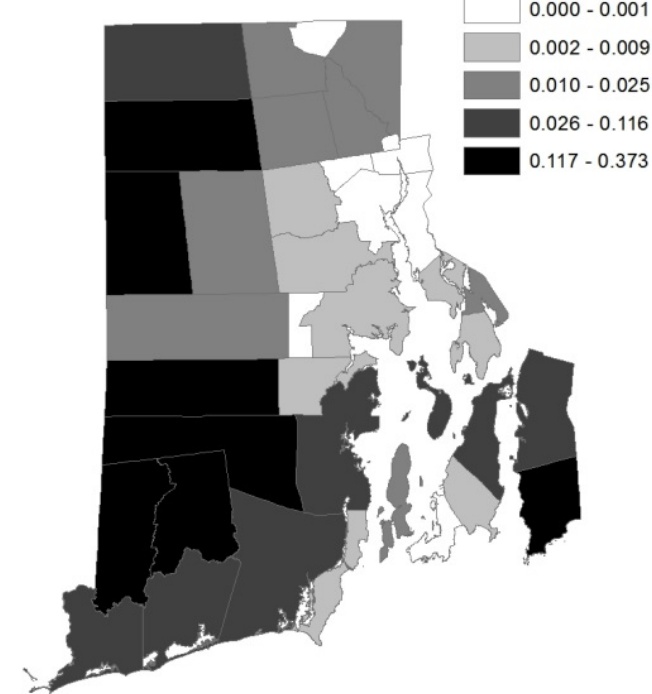

\section{Conservation spending}

Dollars per capita

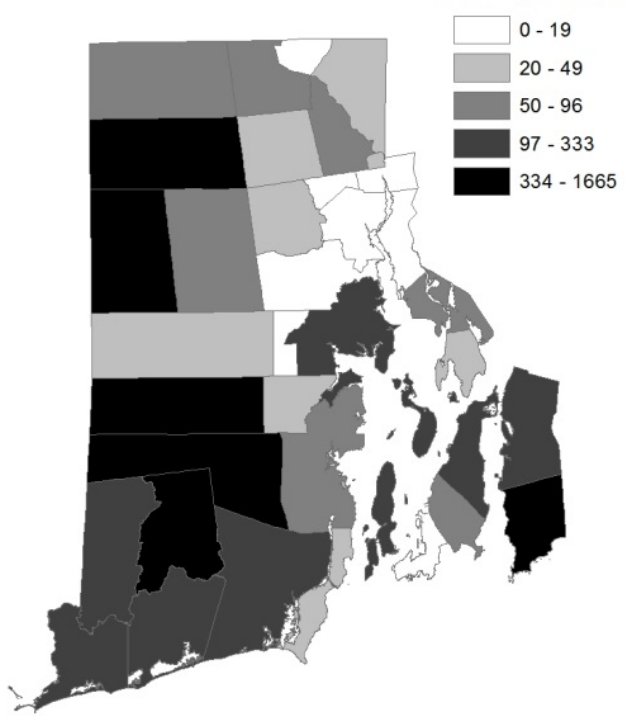

Notes: Population data come from the 2000 Decennial Census. Conservation acres and spending data are from the Land Acquisition Database from the Rhode Island Department of Environmental Management. All data is plotted at the municipal level. 
Figure 2: Illustration of process to match polling locations to census tracts

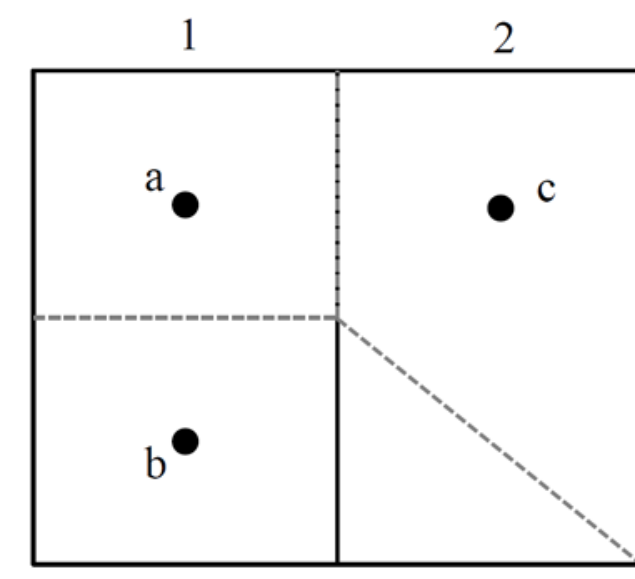

\section{Legend}

- Polling location

\section{- Tract boundary}

Thiessen polygon

boundary separating

polling locations

Notes: There are two tracts, denoted 1 and 2, and three polling location, denoted a, b and c. Thiessen polygons, shown with dashed lines, form boundaries between polling locations, such that boundaries are equidistant between polling locations. Tract level voting outcomes are estimated by calculating the area of each tract composed of each polling location Thiessen polygon, normalizing the area to form weights that sum to one, and then calculating a weighted average of voting outcomes for each tract based on the area. In the illustration, Tract 1's vote is equal to $50 \%$ times polling location a's vote plus $50 \%$ times polling location b's vote and Tract 2's vote is equal to $75 \%$ times polling location c's vote plus $25 \%$ times polling location b's vote. 
Figure 3: Spatial distribution of open space referenda voting by tract

Percent approve 2004

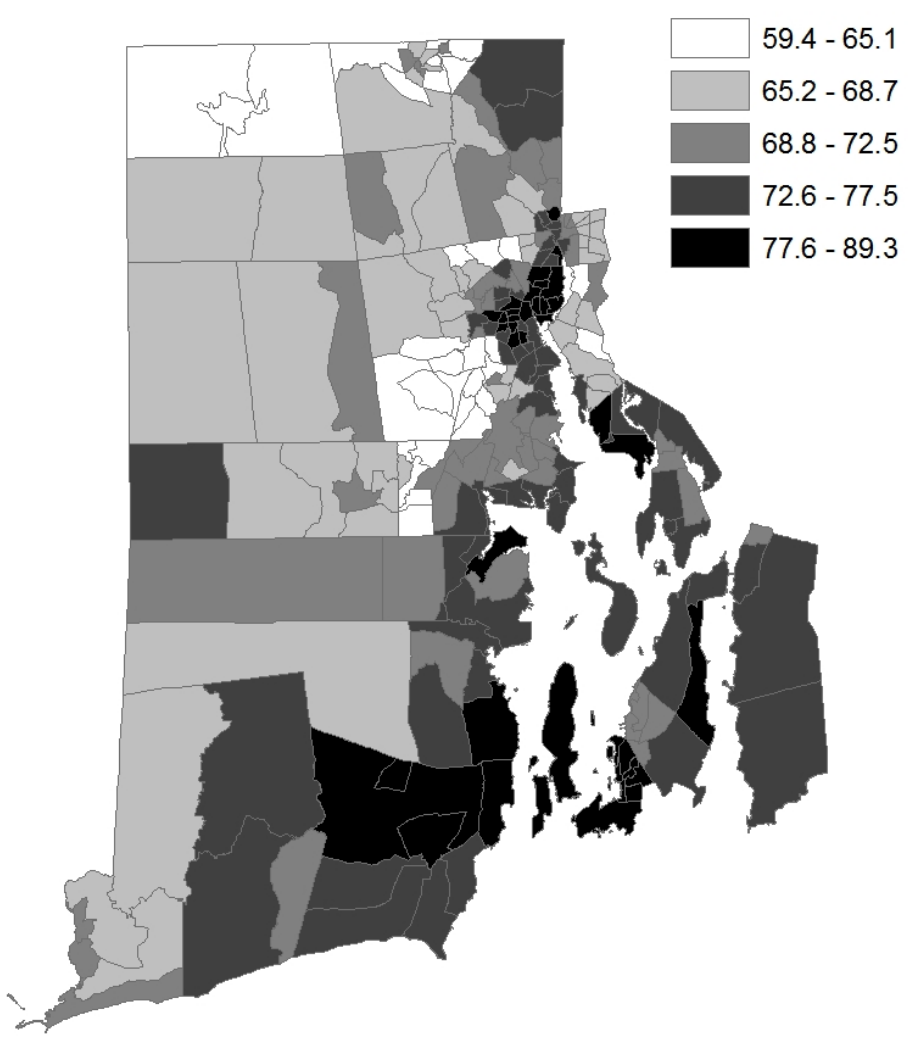

Change in percent approve 2004-2012

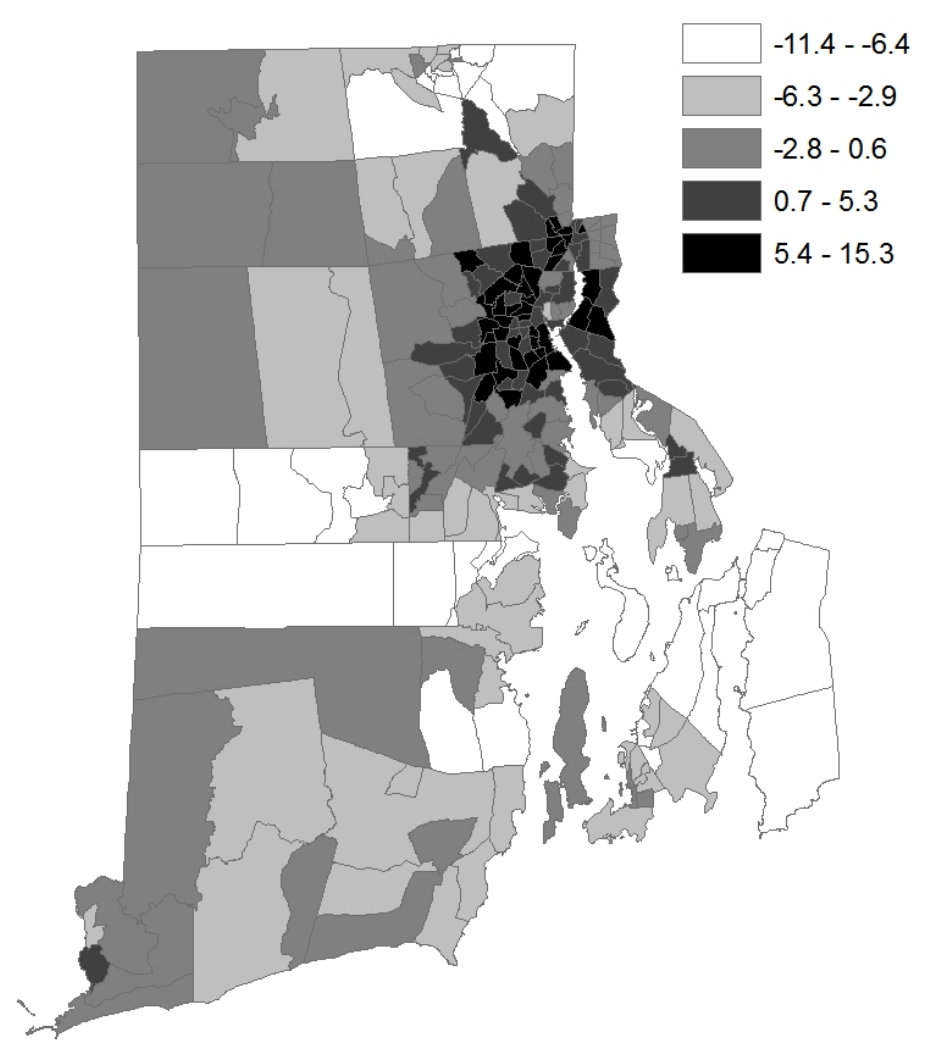

Notes: Both panels display voting outcomes on Rhode Island land conservation referenda. Data come from Rhode Island Board of Elections and is displayed at the tract level. 
Table 1: Summary statistics

\begin{tabular}{lc}
\hline \hline Variable & $\begin{array}{c}\text { Mean } \\
\text { (std. dev.) }\end{array}$ \\
\hline \% approve & 71.49 \\
& $(5.81)$ \\
Change in \% approve 2004-2012 & -0.4 \\
& $(5.29)$ \\
Population density (1000s/sq. mile) & 5.20 \\
& $(4.91)$ \\
\% population growth 2004-2012 & -0.18 \\
& $(6.972)$ \\
\% Democratic vote & 61.74 \\
& $(10.42)$ \\
\% Voter turnout & 16.96 \\
& $(9.49)$ \\
\% black or Hispanic & 9.00 \\
& $(11.26)$ \\
\% High school graduate (or more) & 79.89 \\
& $(12.56)$ \\
\% College graduate (or more) & 20.18 \\
& $(12.28)$ \\
Median Household Income (2004\$) & 49625 \\
& $(18815)$ \\
Unemployment rate & 6.15 \\
& $(3.21)$ \\
\% Under 18 & 21.08 \\
& $(5.42)$ \\
\% Over 65 & 14.04 \\
Number of observations & $(5.14)$ \\
Notes: All variables are for year 2004 unless otherwise noted. \% approve is the \\
percentage of yes votes on conservation referenda. \% Democratic vote is the \\
percentage of votes cast for the Democratic candidate for president. \% voter \\
curnout is the number of votes divided by the population. These variables \\
linearly interpolated between the 2000 Decennial Census and the 2008-2012 \\
American Community Survey, treating the later as occuring in 2010. All \\
observations are at the census tract level. See text for more details. \\
\\
\end{tabular}


Table 2: Determinants of changes in conservation referenda support

\begin{tabular}{|c|c|c|c|c|}
\hline \multirow{3}{*}{ Variable } & \multicolumn{4}{|c|}{$\begin{array}{c}\text { Dependent variable } \\
=\text { change in \% approve 2004-2012 }\end{array}$} \\
\hline & \multicolumn{3}{|c|}{ Direct effects } & \multirow{2}{*}{$\frac{\text { Total effects }}{(4)}$} \\
\hline & (1) & (2) & (3) & \\
\hline \multirow[t]{2}{*}{ Density (1000s/sq. mile) } & $0.346^{* * *}$ & $0.171 * *$ & $0.339 * * *$ & $0.650 * * *$ \\
\hline & $(0.058)$ & $(0.076)$ & $(0.077)$ & $(0.155)$ \\
\hline \multirow[t]{2}{*}{ Growth } & -0.003 & -0.009 & 0.027 & 0.052 \\
\hline & $(0.033)$ & $(0.032)$ & $(0.031)$ & $(0.052)$ \\
\hline \multirow[t]{2}{*}{ Density*growth } & $0.021^{* * *}$ & $0.015^{* *}$ & $0.012^{* *}$ & $0.024 * *$ \\
\hline & $(0.007)$ & $(0.007)$ & $(0.006)$ & $(0.012)$ \\
\hline \multirow[t]{2}{*}{$\Delta \%$ Democrat vote } & & $0.382 * * *$ & $0.407 * * *$ & $0.780 * * *$ \\
\hline & & $(0.075)$ & $(0.070)$ & $(0.172)$ \\
\hline \multirow[t]{2}{*}{ \% Approve 2004} & & & $-0.271 * * *$ & $-0.519 * * *$ \\
\hline & & & $(0.045)$ & $(0.106)$ \\
\hline \multirow[t]{2}{*}{$\Delta \%$ voter turnout } & & $-0.038 *$ & -0.020 & -0.039 \\
\hline & & $(0.021)$ & $(0.019)$ & $(0.040)$ \\
\hline \multirow[t]{2}{*}{$\Delta \%$ high school graduate } & & $0.079 *$ & $0.072 *$ & $0.137^{*}$ \\
\hline & & $(0.041)$ & $(0.038)$ & $(0.079)$ \\
\hline \multirow[t]{2}{*}{$\Delta \%$ college graduate } & & 0.017 & -0.033 & -0.062 \\
\hline & & $(0.028)$ & $(0.027)$ & $(0.054)$ \\
\hline \multirow[t]{2}{*}{$\Delta$ median household income $(000 \mathrm{~s})$} & & 0.000 & 0.035 & 0.066 \\
\hline & & $(0.034)$ & $(0.032)$ & $(0.057)$ \\
\hline \multirow[t]{2}{*}{$\Delta$ median household income (000s) squared } & & -0.000 & -0.001 & -0.002 \\
\hline & & $(0.002)$ & $(0.001)$ & $(0.002)$ \\
\hline \multirow[t]{2}{*}{$\Delta \%$ Unemployed } & & -0.010 & -0.091 & -0.173 \\
\hline & & $(0.061)$ & $(0.058)$ & $(0.109)$ \\
\hline \multirow[t]{2}{*}{$\Delta \%$ Under 18} & & $-0.105^{*}$ & $-0.163^{* * *}$ & $-0.311^{* * *}$ \\
\hline & & $(0.058)$ & $(0.055)$ & $(0.108)$ \\
\hline \multirow[t]{2}{*}{$\Delta \%$ Over 65} & & -0.087 & -0.022 & -0.042 \\
\hline & & $(0.062)$ & $(0.059)$ & (0.119) \\
\hline \multirow[t]{2}{*}{$\Delta \%$ black or Hispanic } & & -0.006 & -0.028 & -0.053 \\
\hline & & $(0.034)$ & $(0.031)$ & $(0.057)$ \\
\hline \multirow[t]{2}{*}{$\rho$ (spatial lag) } & $0.566 * * *$ & $0.527^{* * *}$ & $0.479 * * *$ & \\
\hline & $(0.085)$ & $(0.077)$ & $(0.072)$ & \\
\hline \multirow[t]{2}{*}{$\lambda$ (spatial error) } & $0.531 *$ & $0.744 * * *$ & $0.908 * * *$ & \\
\hline & $(0.334)$ & $(0.181)$ & $(0.064)$ & \\
\hline Adjusted R squared & 0.576 & 0.645 & 0.693 & \\
\hline
\end{tabular}

Notes: Columns 1-3 present results from separate models. Coefficient estimates of direct effects are given. Column 4 gives total effects of each variable based on the estimated direct effect in Column 3 and the estimated spatial lag. Models presented here are SARAR models and use a spatial error and spatially lagged dependent variable term. The spatial lag matrix uses the nearest 10 neighbors and the spatial error matrix uses the entire set of neighbors. In both cases, neighbors are given weights equal to inverse distance (and then row normalized). All models use change in \% approve as the dependent variable and include 232 observations at the tract level. Growth is defined as the percent population growth between 2004 and 2012. We transform the variables density and growth into deviation from mean form such that the coefficients give the marginal effect of density (growth) with growth (density) equal to its mean. Robust standard errors are in parentheses *, ** and *** indicate significance at the $10 \%, 5 \%$ and $1 \%$ level, respectively. 
Table 3: Robustness checks for spatial dependence assumptions

\begin{tabular}{lccccc}
\hline \hline \multirow{2}{*}{ Variable } & \multicolumn{5}{c}{ Dependent variable $=$ change in \% approve 2004-2012 } \\
\cline { 2 - 6 } & $(1)$ & $(2)$ & $(3)$ & $(4)$ & $(5)$ \\
\hline Density (1000s/sq. mile) & $0.339^{* * *}$ & $0.325^{* * *}$ & $0.363^{* * *}$ & $0.374^{* * *}$ & $0.370^{* * *}$ \\
& $(0.077)$ & $(0.076)$ & $(0.079)$ & $(0.075)$ & $(0.077)$ \\
Growth & 0.027 & 0.024 & 0.032 & 0.029 & 0.033 \\
& $(0.031)$ & $(0.031)$ & $(0.031)$ & $(0.029)$ & $(0.029)$ \\
Density*growth & $0.012^{* *}$ & $0.013^{* *}$ & $0.013^{* *}$ & $0.011^{*}$ & $0.012^{* *}$ \\
& $(0.006)$ & $(0.006)$ & $(0.006)$ & $(0.006)$ & $(0.006)$ \\
\hline \multirow{3}{*}{ Spatial assumptions } & lag: nearest 10 & lag: nearest 20 & lag: nearest 20 & lag: nearest 10 & lag: 1 or more \\
& error: all tracts & error: all tracts & error: nearest 20 & error: all tracts & error: 1 or more \\
$\rho$ (spatial lag) & idw power=1 & idw power=1 & idw power=1 & idw power=2 & idw power $=1$ \\
& $0.479^{* * *}$ & $0.555^{* * *}$ & $0.931^{* * *}$ & 0.033 & 0.021 \\
$\lambda$ (spatial error) & $(0.072)$ & 0.079 & 0.310 & $(0.098)$ & $(0.201)$ \\
& $0.908^{* * *}$ & $0.882^{* * *}$ & $0.940^{* * *}$ & $0.932^{* * *}$ & $0.807^{* * *}$ \\
\hline
\end{tabular}

Notes: Each column presents results from a separate model. All models use change in \% approve as the dependent variable and the full set of independent variables used in Column 3 of Table 2. Only coefficient estimates of direct effects are reported. Each column varies the spatial dependence assumptions, as described in the row 'Spatial assumptions', where lag and error describe the number of neighbors given positive weight for those two matrices, respectively, and $\mathrm{p}$ is the power of the inverse distance weighting. Column 1 is identical to Column 3 of Table 2. In Column 5, the matrix ' 1 or more' is constructed as follows: for all tracts, find the minimum distance between that tract and a neighbor, then take the maximum of those minimums, categorize tracts as neighbors if they are within that distance. See Table 2 for more details. 
Table 4: Determinants of changes in conservation referenda support, without spatial dependence

\begin{tabular}{|c|c|c|c|}
\hline \multirow[t]{2}{*}{ Variable } & \multicolumn{3}{|c|}{$\begin{array}{c}\text { Dependent variable } \\
=\text { change in \% approve } 2004-2012\end{array}$} \\
\hline & (1) & (2) & (3) \\
\hline Density (1000s/sq. mile) & $\begin{array}{c}0.620 * * * \\
(0.058)\end{array}$ & $\begin{array}{c}0.329 * * * \\
(0.093)\end{array}$ & $\begin{array}{c}0.472 * * * \\
(0.096)\end{array}$ \\
\hline Growth & $\begin{array}{c}0.086 \\
(0.041)\end{array}$ & $\begin{array}{c}0.059 \\
(0.042)\end{array}$ & $\begin{array}{c}0.093 * * \\
(0.041)\end{array}$ \\
\hline Density*growth & $\begin{array}{c}0.027 * * * \\
(0.009)\end{array}$ & $\begin{array}{l}0.017 * \\
(0.008)\end{array}$ & $\begin{array}{c}0.014 \\
(0.009)\end{array}$ \\
\hline$\Delta \%$ Democrat vote & & $\begin{array}{c}0.363^{* * *} \\
(0.097)\end{array}$ & $\begin{array}{c}0.411 * * * \\
(0.094)\end{array}$ \\
\hline \% Approve 2004 & & & $\begin{array}{c}-0.236 * * * \\
(0.056)\end{array}$ \\
\hline$\Delta \%$ voter turnout & & $\begin{array}{l}-0.040 \\
(0.027)\end{array}$ & $\begin{array}{l}-0.024 \\
(0.027)\end{array}$ \\
\hline$\Delta \%$ high school graduate & & $\begin{array}{c}0.072 \\
(0.054)\end{array}$ & $\begin{array}{c}0.060 \\
(0.052)\end{array}$ \\
\hline$\Delta \%$ college graduate & & $\begin{array}{l}-0.010 \\
(0.035)\end{array}$ & $\begin{array}{l}-0.065^{*} \\
(0.037)\end{array}$ \\
\hline$\Delta$ median household income $(000 \mathrm{~s})$ & & $\begin{array}{l}-0.000 \\
(0.044)\end{array}$ & $\begin{array}{c}0.037 \\
(0.044)\end{array}$ \\
\hline $\begin{array}{l}\Delta \text { median household income }(000 \mathrm{~s}) \\
\text { squared }\end{array}$ & & 0.001 & 0.001 \\
\hline & & $(0.002)$ & $(0.002)$ \\
\hline$\Delta \%$ Unemployed & & $\begin{array}{c}0.032 \\
(0.080)\end{array}$ & $\begin{array}{l}-0.045 \\
(0.079)\end{array}$ \\
\hline$\Delta \%$ Under 18 & & $\begin{array}{c}-0.196 * * * \\
(0.075)\end{array}$ & $\begin{array}{c}-0.252 * * * \\
(0.074)\end{array}$ \\
\hline$\Delta \%$ Over 65 & & $\begin{array}{c}-0.260 * * * \\
(0.079)\end{array}$ & $\begin{array}{c}-0.183 * * \\
(0.078)\end{array}$ \\
\hline$\Delta \%$ black or Hispanic & & $\begin{array}{c}0.051 \\
(0.043)\end{array}$ & $\begin{array}{c}0.025 \\
(0.042)\end{array}$ \\
\hline Adjusted R squared & 0.348 & 0.465 & 0.505 \\
\hline
\end{tabular}

Notes: Each column presents results from a separate model. All models use change in \% approve as the dependent variable and include 232 observations at the tract level. Growth is defined as the percent population growth between 2004 and 2012. We transform the variables density and growth into deviation from mean form such that the coefficients give the marginal effect of density (growth) with growth (density) equal to its mean. Robust standard errors are in parentheses *, ** and *** indicate significance at the $10 \%, 5 \%$ and $1 \%$ level, respectively. 
Table 5: Cross-sectional determinants of conservation referenda support

\begin{tabular}{|c|c|c|c|c|}
\hline \multirow{3}{*}{ Variable } & \multicolumn{4}{|c|}{ Dependent variable $=\%$ approve } \\
\hline & \multicolumn{2}{|c|}{2004} & \multicolumn{2}{|c|}{2012} \\
\hline & $\begin{array}{c}\text { Direct effect } \\
\text { (1) }\end{array}$ & $\begin{array}{c}\text { Total effect } \\
\text { (2) }\end{array}$ & $\begin{array}{c}\text { Direct effect } \\
\text { (3) }\end{array}$ & $\begin{array}{c}\text { Total effect } \\
\text { (4) }\end{array}$ \\
\hline \multirow[t]{2}{*}{ Density (1000s/sq. mile) } & 0.128 & 0.182 & 0.006 & 0.007 \\
\hline & $(0.081)$ & $(0.115)$ & $(0.086)$ & $(0.369)$ \\
\hline \multirow[t]{2}{*}{ Growth } & $0.052 * *$ & $0.075^{* *}$ & -0.046 & -0.063 \\
\hline & $(0.022)$ & $(0.033)$ & $(0.034)$ & $(0.043)$ \\
\hline \multirow{2}{*}{ Density*growth } & -0.010 & -0.015 & 0.073 & 0.100 \\
\hline & $(0.043)$ & $(0.067)$ & $(0.060)$ & $(0.090)$ \\
\hline \multirow[t]{2}{*}{ \% Democrat vote } & $0.170^{* * *}$ & $0.242 * * *$ & $0.449 * * *$ & $0.612 * * *$ \\
\hline & $(0.052)$ & $(0.075)$ & $(0.039)$ & $(0.059)$ \\
\hline \multirow[t]{2}{*}{$\%$ voter turnout } & 0.041 & 0.059 & -0.003 & -0.004 \\
\hline & $(0.026)$ & $(0.044)$ & $(0.014)$ & $(0.013)$ \\
\hline \multirow[t]{2}{*}{ \% high school graduate } & 5.220 & 7.453 & $7.675^{* *}$ & $10.475^{* *}$ \\
\hline & $(5.392)$ & $(8.418)$ & (3.026) & $(4.316)$ \\
\hline \multirow[t]{2}{*}{$\%$ college graduate } & $28.004 * * *$ & $39.983 * * *$ & $7.434 * * *$ & $10.147 * * *$ \\
\hline & $(4.391)$ & (6.919) & $(2.828)$ & $(3.846)$ \\
\hline \multirow[t]{2}{*}{ Median household income (000s) } & -0.122 & -0.174 & -0.030 & -0.040 \\
\hline & $(0.076)$ & $(0.099)$ & $(0.048)$ & $(0.077)$ \\
\hline \multirow[t]{2}{*}{ Median household income (000s) squared } & 0.480 & 0.685 & $0.789^{* *}$ & $1.076 * *$ \\
\hline & $(0.553)$ & $(0.672)$ & $(0.350)$ & $(0.493)$ \\
\hline \multirow[t]{2}{*}{ \% Unemployed } & 0.081 & 0.115 & -0.020 & -0.027 \\
\hline & $(0.106)$ & $(0.167)$ & $(0.061)$ & $(0.084)$ \\
\hline \multirow[t]{2}{*}{ \% Under 18} & 0.045 & 0.063 & $-0.180 * * *$ & $-0.246 * * *$ \\
\hline & $(0.073)$ & $(0.098)$ & $(0.051)$ & $(0.072)$ \\
\hline \multirow[t]{2}{*}{ \% Over 65} & $-0.148 * * *$ & $-0.210 * * *$ & $-0.081^{* *}$ & $-0.111^{* *}$ \\
\hline & $(0.050)$ & $(0.075)$ & $(0.038)$ & $(0.051)$ \\
\hline \multirow{2}{*}{$\%$ black or hispanic } & 0.020 & 0.0283 & $0.060^{* *}$ & $0.081 * *$ \\
\hline & $(0.056)$ & $(0.108)$ & $(0.026)$ & $(0.036)$ \\
\hline \multirow[t]{2}{*}{$\rho$ (spatial lag) } & $0.300 * * *$ & & $0.267 * * *$ & \\
\hline & $(0.076)$ & & $(0.055)$ & \\
\hline \multirow[t]{2}{*}{$\lambda$ (spatial error) } & $0.857 * * *$ & & $0.931 * * *$ & \\
\hline & $(0.098)$ & & $(0.047)$ & \\
\hline Adjusted R squared & 0.690 & & 0.846 & \\
\hline
\end{tabular}

Notes: Columns 1 and 3 present cross sectional regression results with \% approve as the dependent variable. Column 1 (3) uses voting data and interpolated census data from 2004 (2012), with population growth measured in the past 10 years. We transform the variables density and growth into deviation from mean form such that the coefficients give the marginal effect of density (growth) with growth (density) equal to its mean. The spatial formulation is identical to the models presented in Table 2. Column 2 (4) gives total effects of each variable based on the estimated direct effect in Column 1 (3) and the estimated spatial lag. Robust standard errors are in parentheses *, ** and *** indicate significance at the $10 \%, 5 \%$ and $1 \%$ level, respectively. 